\title{
The changing face of rabies in Canada
}

\author{
Filejski $C^{1 *}$
}

\section{Abstract}

Rabies prevention and control programs in Canada have proven highly successful in past decades and have significantly reduced both terrestrial animal and human rabies cases. Successful management and prevention of rabies to date have not, however, eliminated our need for ongoing rabies prevention and control programs.

This issue of the Canadian Communicable Disease Report (CCDR) provides an overview of recent and emerging rabies trends and challenges in Canada and examines the rationale to maintain our rabies programs and further supplement them with new and innovative approaches. The articles in this issue cover a broad range of topics including the preparation for, and response to, renewed incursions of the raccoon rabies variant of the virus, how to address the problem posed by the movement of dogs from northern to southern Canada and how the Canadian Rabies Management Plan is being revised and updated to respond to these issues.

Rabies in Canada is changing, but it is not disappearing. The same needs to be said of our rabies prevention and control policies and programs.

\section{Affiliation}

${ }^{1}$ Public Health Veterinarian, Ontario Ministry of Health and Long-Term Care, Toronto, ON

*Correspondence: catherine. filejski@ontario.ca

Suggested citation: Filejski C. The changing face of rabies in Canada. Can Comm Dis Rep 2016;42:118-20. https://doi.org/10.14745/ccdr.v42i06a01

\section{Introduction}

After decades of success in preventing human rabies cases and significantly reducing rabies in terrestrial mammal populations in Canada, questions have begun to surface about the real value and utility of continuing our rabies prevention and control programs. In an era of fiscal restraint and competing infectious disease priorities, do we really need to continue to investigate all bites and exposures which may result in the transmission of rabies to humans? After all, human rabies cases are exceptionally rare in Canada-in the first decade of the twenty-first century, there were only three domestically acquired cases, all due to bat strains of rabies (1). On the wildlife front, Ontario (the province once known as the "rabies capital of North America") had successfully eradicated the raccoon strain of rabies from its eastern regions in 2005; was declared "raccoon rabies free" in 2008 (2); and reported only two cases of terrestrial rabies due to fox strain rabies in 2011 (3). In many circles, complacency about rabies prevention and control was beginning to set in.

\section{New trends and challenges}

Unfortunately, by 2012, new threats and challenges in rabies prevention and control in Canada began to emerge and today, the face of rabies in Canada is far less rosy than it appeared to be four years ago. This special rabies-themed issue of the Canada Communicable Disease Report (CCDR) explores recent changes and new trends in rabies risk across a number of provinces.

\section{Raccoon rabies strains return}

Rabies continues to pose a significant risk to both public and animal health in Canada for a number of reasons. Firstly, although prevention and control efforts in wildlife have dramatically decreased the number of animal cases in southern Canada, rabies remains a significant problem in the United States (US) and the threat of rabies virus incursions over the border into Canadian provinces remains real and constant. In this issue, Stevenson et al. report on three renewed incursions of the raccoon rabies strain which has found its way back into New Brunswick, Quebec and Ontario over the past two years (4).

\section{Arctic fox rabies strains remain}

Despite the low number of terrestrial rabies cases in southern Canada, the Arctic fox variant strain of rabies remains endemic in northern Canada and there are no real prospects for its elimination. In the north, Arctic fox populations tend to cycle through rabies outbreaks which can become significant enough to spill over and affect both dog populations in northern communities and red fox populations in the south. Movement of the fox rabies virus strain between various animal populations has, in fact, had significant consequences in the past. In the mid-1950s, the spillover of an Arctic fox rabies outbreak in the north into more southern red fox populations led to the movement of fox rabies into southern Ontario and Quebec (5).

\section{The trouble with translocation}

More recently, in the winter of 2011-2012, events linked to a significant Arctic fox rabies outbreak in northern Quebec (Nunavik) and western Labrador led to the identification of a new and growing rabies concern in Canada-the introduction 
of rabies into highly-populated urban areas due to translocation (rapid movement across large distances) of dogs from the north. In the midst of the 2011-2012 rabies outbreak, an animal protection organization was rescuing stray dogs from northern Quebec and finding them new homes in the south. The result of these activities was the translocation of rabid puppies from Nunavik to Montréal in January of 2012 (6). Rather than being an isolated incident, this initial case was the first indication of trouble brewing on the horizon as a growing flow of unowned dogs were moved from remote northern communities to new adoptive homes in the south. In the second article in this issue, Curry et al. report on two subsequent cases involving translocation of rabid dogs into two different provinces (7).

\section{A global problem}

The importation or translocation of rabid dogs has also occurred in the US and Europe and has generated increased concern from public health authorities. Requirements for rabies vaccination certificates for dogs crossing international borders (as a means of preventing the spread of rabies) are being sabotaged. In January 2014, the National Association of State Public Health Veterinarians urged the United States Centers for Disease Control and Prevention (US CDC) to revise and expand existing importation regulations for dogs, which dated back to the 1950s because they did not "adequately reduce the risk that a rabid animal will enter the US" (Personal correspondence from National Association of State Public Health Veterinarians, Inc. (NASPHV) President and NASPHV Rabies Compendium Committee Chair to the Director of the US CDC, January 14, 2014. http://tinyurl. com/lpmou79). In May 2014, the US CDC issued a Health Alert on Imported Dogs with Questionable Documentation noting reports of questionable vaccination certificates for an increasing number of dogs who had been imported into the US from rabies-endemic countries (8). Their concern proved warrantedin May 2015, a dog imported into the US from Egypt was diagnosed with rabies and found to have entered the US with a falsified rabies vaccination certificate (9). Growing concerns about the risks of importation (or even translocation) of domestic animals that have not been adequately vaccinated against rabies are now increasingly being voiced not only in Canada and the US, but also Europe and the United Kingdom (10).

\section{Innovative approaches}

Canada faces similar issues regarding the importation of dogs across our borders. And, as Curry et al. illustrate, translocation poses an additional problem because animal transportation within country borders does not require rabies vaccination certificates. Reducing the risk of rabies due to translocation of dogs from the north to the south within Canada will require innovative solutions to control dog population numbers (i.e., slowing the flow of dogs or stopping it altogether) and to improve canine rabies vaccination rates in remote northern communities. Lidstone-Jones and Gagnon report on an innovative approach to dog population management which is being piloted along Ontario's James Bay and Hudson Bay coastlines, using injectable contraceptive in female dogs (11). While not traditionally considered a rabies prevention and control measure, it is becoming increasingly clear that effective and sustainable dog population management strategies in the north are an important component of rabies prevention for both northern and southern Canadian communities.

\section{Interjurisdictional coordination}

It is likely that bat rabies will remain endemic in Canada for the foreseeable future. This fact, as well as the re-appearance of raccoon rabies in New Brunswick, Quebec and Ontario, the growing numbers of translocated rabid dogs and the dog overpopulation challenges faced by our remote northern communities in Canada all serve to emphasize the importance of continued vigilance in rabies prevention and control.

The complexity of successfully managing rabies on a national scale was reflected in the development of the Canadian Rabies Management Plan. The Plan was initially signed by the Canadian Food Inspection Agency and the Public Health Agency of Canada in 2009 and provides an overview of rabies-related roles, responsibilities and activities across the country. However, federal rabies program changes implemented in 2014 have significantly altered those roles, responsibilities and activities in Canada. In the last article of this issue, Tataryn and Buck provide a brief overview of how the Canadian Rabies Management Plan is being revised and updated to reflect not only those changes, but also the new challenges Canada faces with respect to rabies prevention and control (12).

\section{Conclusion}

The new reality is that translocation of animals, whether wild or domesticated, can drastically change an area's local rabies risk picture from one day to the next. This means that traditional measures of rabies risk, based exclusively on local rabies case counts, need to be balanced and supplemented by other considerations, including animal movement into and out of a region. Fresh approaches are needed to address the new reality of rabies in Canada, such as new oral rabies wildlife vaccines, more efficient interjurisdictional collaboration and innovative northern dog population management strategies. Rabies in Canada is changing, but it is not disappearing. The same needs to be said of our rabies prevention and control policies and programs.

\section{Acknowledgements}

Dr. Catherine Filejski was a guest editor for this issue and recused herself from the editorial decisions involved in this manuscript. Editorial decisions were made by Dr. Erika Bontovics, Guest Editor for this issue and Dr. Patricia Huston, Editor-in-Chief of the CCDR.

\section{Conflict of interest}

None. 


\section{References}

1. National Advisory Committee on Immunization (NACl). Rabies vaccine. In: Canadian immunization guide. Ottawa: Public Health Agency of Canada; 2014. http://www.phacaspc.gc.ca/publicat/cig-gci/.

2. Ontario Ministry of Natural Resources. Rabies reporter, Summer 2008. MNR Publication 51709, Vol 19(2), 2008.

3. Ontario Ministry of Natural Resources. Rabies reporter, Oct-Dec 2011. MNR Publication 51709, Vol 22(4), 2011.

4. Stevenson B, Goltz J, Massé A, et al. Preparing .for and responding to recent incursions of raccoon rabies variant rabies into Canada. Can Comm Dis Rep 2016;42:125-9.

5. Lagacé F. Historique de la rage au Québec de 1958 à 1997. Le Médecin Vétérinaire du Québec 2008;28(3).

6. Ministère de la Santé et des Services sociaux du Québec. Vigie-interventions : Rage chez des chiots. Flash Vigie Feb $2012 ; 7(2)$.
7. Curry P, Kostiuk D, Werker DH, Baikie M, Ntiamoah W, Atherton F, et al. Translocated dogs from Nunavut: The spread of rabies. Can Comm Dis Rep 2016;42:121-4.

8. CDC warns of flawed rabies certificates. JAVMA Jul 2014;245(1). https://www.avma.org/News/JAVMANews/ Pages/140701k.aspx.

9. Sinclair D, Wallace RM, Gruszynski K, Bibbs Freeman M, Campbell C, Semple S, et al. Rabies in a dog imported from Egypt with a falsified rabies vaccination certificate: Virginia, 2015. MMWR Dec 2015;64(49).

10. Ford E. Government urged to review rabies risk. BBC News. 2013 Oct 20. http://www.bbc.com/news/uk-24569593.

11. Lidstone-Jones C, Gagnon R. Northern innovation in rabies prevention and control: The WAHA Dog Population Management Pilot Project. Can Comm Dis Rep 2016;42:1304.

12. Tataryn J, Buck PA. The Canadian Rabies Management Plan: An integrated approach to the coordination of rabies activities in Canada. Can Comm Dis Rep 2016;42:135-6.

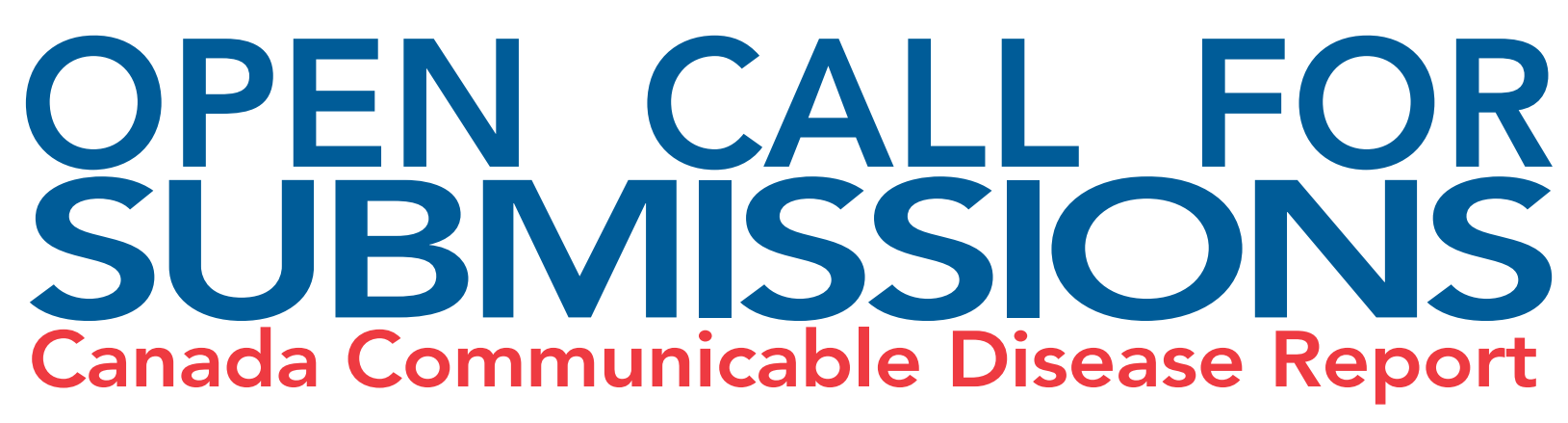

In 2015, we published articles with authors from almost all provinces and territories.

We welcome submissions of manuscripts with practical, authoritative information on infectious diseases that will inform policy, program and practice.

\section{Visit: www.phac-aspc.gc.ca/publicat/ccdr-rmtc/ia-ra-eng.php}

